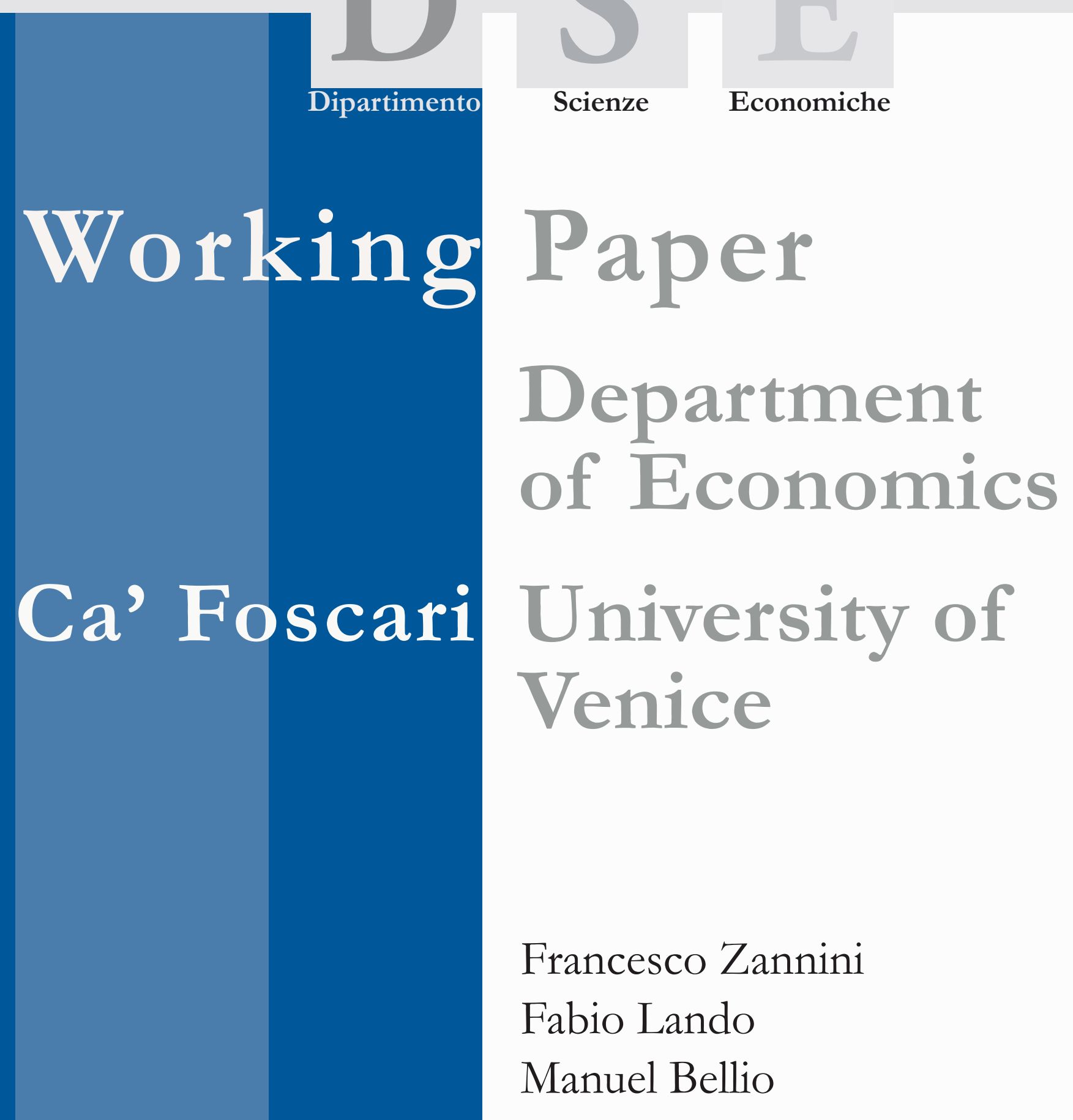

Effects of Tourism on Venice:

Commercial Changes

over 30 Years 


\title{
Effects of Tourism on Venice: Commercial Changes over 30 Years
}

\author{
Francesco Zanini \\ Fabio Lando \\ Manuel Bellio \\ Ca’ Foscari University of Venezia
}

First Draft: June 2008

\begin{abstract}
Tourism is becoming one of the most important economic drivers in the urban context. With this in mind, several cities have tried to adapt their economies to satisfy the demands of the influx of tourism. The main consequences of this trend are the re-shaping of urban areas, with particular regard to art cities. This phenomenon is particularly evident in Venice's historical city centre. In order to better comprehend the changes that have taken place, we have put together a research based analysis of the commercial structure of the city. Particular attention has been given to comparing and contrasting the retail business over the last thirty years
\end{abstract}

\section{Keywords}

commercial structure, historical city centre, retail, Venice

JEL Codes

$\mathrm{R} 1$ ， R11， R12

Address for correspondence:

Francesco Zanini zanini@unive.it

Fabio Lando lando@unive.it

Department of Economics Ca’ Foscari University of Venice Cannaregio 873, Fondamenta S.Giobbe 30121 Venezia - Italy

Phone: (++39) 0412349160

Fax: (++39) 0412349176

This Working Paper is published under the auspices of the Department of Economics of the Ca' Foscari University of Venice. Opinions expressed herein are those of the authors and not those of the Department. The Working Paper series is designed to divulge preliminary or incomplete work, circulated to favour discussion and comments. Citation of this paper should consider its provisional character.

The Working Paper Series
is availble only on line
(www.dse.unive.it/pubblicazioni)
For editorial correspondence, please contact:
wp.dse@unive.it

Department of Economics

Ca' Foscari University of Venice

Cannaregio 873, Fondamenta San Giobbe

30121 Venice Italy

Fax: ++390412349210 


\section{Introduction $^{1}$}

Urban tourism is not a new phenomenon (Raffestin 1991a; 1991b). Cities have always welcomed tourists and, in certain cases, some parts of the urban context have been constructed and transformed for the purpose of both attracting and encouraging them: Venice represents both these characteristics particularly well. For instance, both the waterfronts and its unique central square (St. Mark's Square) were developed for the purpose of receiving tradesmen arriving by sea (this was the only way that the conurbation could be reached in the past). The Doges deliberately chose to build certain parts of the city with a view to advertising its economic grandeur and to welcoming foreigners.

Although the latter traveled to Venice to conduct and conclude business transactions, they were not indifferent to the beauty of the city. They too were attracted by the arts, the monuments and the atmosphere which are the main pull factors for Venice's current day tourists.

The attitude of tourists has indubitably changed since the advent of mass tourism, and as a consequence, art cities seem to be both more dependent and vulnerable to the demands of tourism compared to the past. One of the macroscopic effects of tourism is the modification of land use with regard to both housing and stores. Venice presents a perfect case study of a large art city and an effective model on which to base research into the effects which tourism can have (Zanetto and Calzavara 1991). Two main transformation periods emerge, in particular, as far as housing is concerned. The first refers to the upgrading of the area around St Mark's, triggered by the increase of second home acquisition (Lando and Zanetto 1978; Costa, Lando and Zanetto 1980); the second refers to the increased number of houses that have been refurbished and dedicated to extra-hotel services (Barbiani and Zanon 2004).

\footnotetext{
${ }^{1}$ The paper is the result of common reflections. Nevertheless, it is possible to attribute to Manuel Bellio the elaboration of the GIS data and figure. This paper is part the outcomes thanks to a PRIN project (year 2005 - prot. 2005111118_006).
} 
What interests us in particular are the effects determined by changes in land use more specifically with reference to the commercial sector - the stores. This paper focuses on the analysis of transformations related to the retail shops in Venice's historical city centre based on research carried out in two distinct periods, 1976 and 2007. The study also includes the evaluation of the five principle routes exploited by tourists in order to reach the major sites and attractions of the city. The objectives are aimed at a better understanding of the evolution of the commercial structure over the last thirty years, the effects that tourism has on the city and, indirectly, to present a methodology which could apply to other art cities.

\section{The effects of tourism on the commercial structure of Venice's historical city centre}

Modern day tourism has led to an ever-increasing number of tourists traveling around the world, especially those from developed countries. Compared to the past, some of the changes that have occurred in modern tourism have been determined by the amount of disposable income available, greater inquisitiveness concerning our surroundings which, in turn, stems from an increase in average cultural levels and the major presence of transport connections and hubs (low cost airlines play an important role) to name but a few. The modified approach to tourism has determined enormous changes to the destination areas - cities in particular during the different stages of development (Butler 1980) and has inevitably brought about an increase in undesirable effects (Russo 2002a, 2002b). In his analysis, Russo (2002b) sees this as the "vicious circle effect" of tourist development in heritage destinations. Several negative effects have been identified, two of which are extremely pertinent to our study: the increase in volumes and congestion and the tourist penchant towards exclusively visiting the main attractions. These phenomena have determined the reshaping of the entire commercial structure of the city and made it possible to define patterns and pathways which have been created by the flow of tourists and which enable them to more rapidly access the final destination of their journey.

Therefore, the tourist phenomenon alters the existing system by pushing the city increasingly towards a tourism mono-culture and contemporaneously reducing the variability of economic activities present in the area and, as a consequence, subjecting the entire local non-tourist economy towards potential decline (Van der Borg 1991; Van der Borg and Costa 2004). This is particularly valid if we take into account the consideration that 'a place cannot be considered to exist separately from what happens there. They are fluid entities that change depending on the mobilities, performances, and encounters ongoing among and between a range of actors at any given time' (Quinn 2007:460).

Nowadays, this affirmation is even more valid than in the past, especially considering the sizeable changes that have occurred in the urban structure over recent years (Knox 1991). For the above reasons and considering that one of the most determing elements in urban geography is the localization 
of the retail activities (Bonetti 1971), this paper attempts to analyze the changes that have taken place in the commercial structure of Venice's historical city centre over the last thirty years. The main goal is to analyze the existing and potential imbalance of activities between those which exclusively target tourists and those reserved for residents and commuters. The changes are indeed strongly related to shifts in the demand, massive depopulation, the violent impact of tourism and the increasing number of work commuters connected to both the University and the tertiary activities present in the city.

\section{Tourists and Non-Tourists in Venice}

Calculating the total number of tourists who visit a city is one of the most difficult analyses to undertake. Nevertheless, some estimations regarding Venice's historical city centre have been defined (Manente and Rizzi 1993; Manente and Montaguti 2004). An update of these estimates gives an idea of the extent of the phenomenon: the total number of tourists is calculated at $22,080,717$, of which: 5,387,695 are overnight stays in the historical city centre; improper day-trippers total 8,037,381; other day-trippers are $8,655,641$.

The positive trend of tourism seems to be continuously on the increase and tourist flows repeatedly exceed the carrying capacity of the city even if the threshold has been raised to 30,000 tourists per day (Van der Borg and Costa 2004), compared to the previous estimation fixed at 25,000 (Costa and Van der Borg 1988). As Van der Borg and Russo observe, 'such a model interprets the conflict taking place between tourists and resident population over the use of urban functions' (Van der Borg and Russo 2001:167). Furthermore, the authors suggest that 'these values can be subjected to a new estimation, taking both the changed propensities in the city's use (redistribution in favour of the amount of day-trippers) and the variations in the considered constraints into account' (Van der Borg and Russo 2001:190).

The calculation of the carrying capacity highlights the level of pressure inflicted by the tourists on a given place. In fact, 'with reference to the estimates made by Costa and Van der Borg (1988), the critical limit [in Venice] was exceeded by 156 days in 1987 and will be exceeded ceteris paribus by 216 days in the year 2000' (Van der Borg and Russo 2001:167). Added to the generally huge number of tourists, two of the biggest problems which exacerbate the figures are the peak periods when the high concentration of tourists is in concomitance with special events (Biennale exposition, Festival of Cinema, Carnival, Redentore, etc.) and the tourist season which is concentrated between the period between April and October.

Consequently, the total quantity of tourists determines enormous demands on the city and stress at economic, social and cultural levels. One of the most noticeable effects is the depopulation of the city's historical centre. In fact, the population has decreased from 102,269 residents in 1976 to 62,296 in 2006. Several determining factors have contributed to this downward trend, such as the higher cost of goods (food, clothes etc.) and 
services (the production of solid waste is one of the major issues with regard to the relationship between tourists and residents), the reduction of services (private and public) especially in marginal areas, the congestion of the city and the transportation system, and the level of crowding around the city.

The presence of work-commuters add to the pressure of these stress factors. Although an accurate calculation of the total number is very difficult, the total amount of people who arrive in Venice on a daily basis for job-related reasons is estimated at around 37,728. More specifically, it has been observed that 62,222 people arrive in the city while 17,414 leave the historical centre. Taking into consideration holidays, festivities and the student population summer break, the net assets total approximately 37,728 entries (Comune di Venezia 2006). Although these are estimated data, they are particularly significance if they are added to the number of tourists and residents present in the city. In particular, while the total number of people present in the city exceeds the reception capacity on the one hand; their impact on the commercial sector is inevitable on the other.

\section{The Methodology Applied}

The data collected for this study derived from two personal censuses carried out in 1976 and in 2007 respectively. The first census, concentrated on and collected data for the month of September, while the second was based on the month of July. The censuses were carried out by means of "walk - abouts" around Venice's historical centre for the purpose of collecting information which had correlation between the location (address) and typology of stores. The criteria adopted to define the various (almost eighty) of retail store types was based on the merchandise displayed in the shop windows. This criteria was considered to be the most suitable when classifying the outlets considering their strong dependency on demand. The decision to concentrate on the merchandise displayed in the shop windows was also motivated by the fact that even the last census made it virtually impossible to define the type of goods sold by each individual store based solely on allocation and registration data from the Chamber of Commerce. Furthermore, each shop often offers more than one commercial activity or product. Retailers are able to offer several types of good which frequently bear no relationship to one another (typical cases are the newspaper kiosks and tobacconists that also sell Venetian souvenirs and toys, and bakeries who sell bread and cakes as well as sandwiches and soft drinks).

The data collected was processed using the Geographical Information System (GIS) in order to minimize calculation errors and to allow for the data to be analyzed and processed, especially regarding the areas known as Sestieri (similar to neighborhoods) and the pathways. The urban context was analyzed by means of a codified subdivision of the historical city centre. In fact, the main island of Venice is divided into Sestieri which represent the units which territorially separate Venice. There are six Sestieri: Santa Croce, Cannaregio, Castello, San Marco, San Polo and Dorsoduro. Our analysis also includes the Giudecca which has similar characteristics to a Sestiere and which is Venice's most important residential island. (Figure 1). 
Figure 1. Structure of the historical city centre of Venice and its tourist pathways

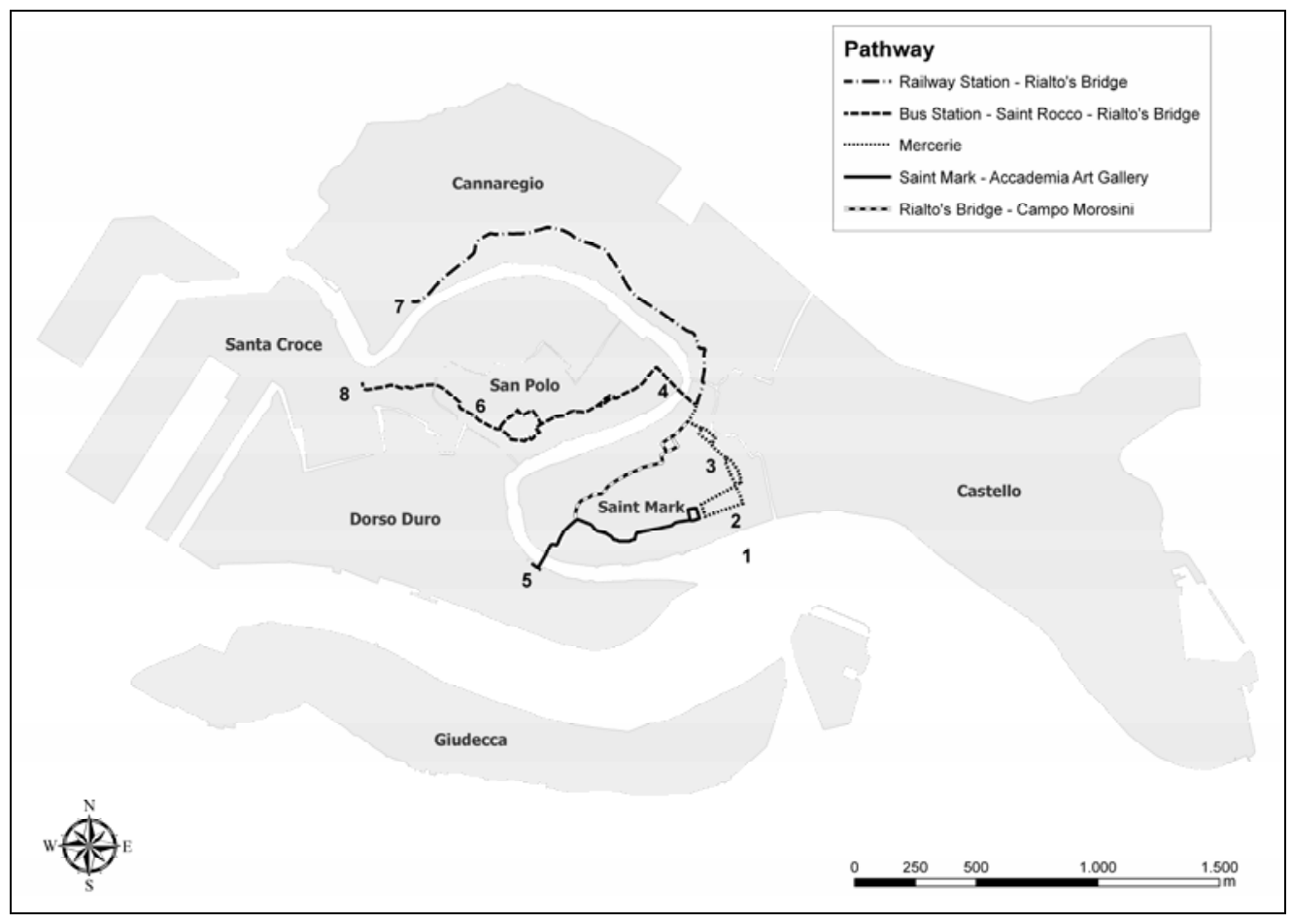

1-Saint Mark’s Basin; 2-Saint Mark’s Square; 3-Mercerie; 4-Rialto Bridge; 5-Accademia Art Gallery; 6-Saint Rocco; 7-Railway Station; 8-Bus Station.

Subsequently, the information obtained regarding retail shops was grouped into five macro-categories. The first regards "retail shops" dedicated to tourist souvenirs. These shops are exclusively, or almost exclusively, dedicated to tourists. Typical goods included in this section are masks, glass items, printed matter and lace. The goods are easily identifiable and not aimed at residents and work-commuters. The second concerns "public outlets" such as bars, restaurants and pizzerias, while, hotels and inns are excluded. The destination of the supply is hybrid, targeting residents and people that cannot reach their own area of residence, such as tourists and work-commuters. The third deals with "clothes' stores". They target residents in particular, although some changes are taking place, especially regarding Italian fashion and design, as more and more tourists are increasingly attracted by the "grand shopping tour". The fourth refers to "grocery stores" dedicated for the quasi totality to residents. And lastly, the fifth category has been denominated "other shops". It includes all the structures not incorporated into the previous macro-categories. These shops, in some cases, satisfy the day to day demands of the residents (florists, barbers, ironmongers, retailers and sellers of household appliances, etc.) while in other cases they focus on metropolitan products (jewelers, furriers, etc.). 
The same analysis approach was applied to five main pathways (Figure 1) mapped out and defined by tourist flows.

\section{The Dynamics of the Retail Store}

Stores evaluated during the period increased by 148 units (Table 1). Although the total amount of new outlets is not surprisingly high, what is important is their composition. Particularly noticeable is the decrease of outlets dedicated to residents, especially grocery stores which stand at $61.67 \%$ (-444 units) and those shops included in the "others" category which register a negative trend of $-23.69 \%$ (-348 units). Conversely, stores entirely dedicated to tourists show an enormous increase of 694 units $(+229 \%)$. The $+10 \%$ increase in apparel stores is directly attributable to the influence of tourism. Finally, public stores increased by almost $+27.5 \%$ $(+189$ units) as direct result of tourists and work-commuters.

Table 1. Shops categories

\begin{tabular}{lrrrrrr}
\hline & \multicolumn{4}{c}{$\boldsymbol{c}$} & \multicolumn{2}{c}{$\boldsymbol{\mathbf { 2 0 0 7 - 1 9 7 6 }}$} \\
\hline & $\mathbf{1 9 7 6}$ & $\mathbf{\%}$ & $\mathbf{2 0 0 7}$ & \% & Total & \% \\
\hline Tourist shops & 303 & 8.17 & 997 & 25.85 & 694 & 229.04 \\
Public shops & 688 & 18.55 & 877 & 22.74 & 189 & 27.47 \\
Clothes' shops & 529 & 14.26 & 586 & 15.19 & 57 & 10.78 \\
Grocery stores & 720 & 19.41 & 276 & 7.16 & -444 & -61.67 \\
Other shops & 1469 & 39.61 & 1121 & 29.06 & -348 & -23.69 \\
Total & $\mathbf{3 7 0 9}$ & $\mathbf{1 0 0 . 0 0}$ & $\mathbf{3 8 5 7}$ & $\mathbf{1 0 0 . 0 0}$ & $\mathbf{1 4 8}$ & $\mathbf{3 . 9 9}$ \\
\hline
\end{tabular}

It is necessary to point out that this re-shaping trend has inverted both the number and level of importance of two important store categories; one dedicated to tourists and the other to residents (grocery stores).

Table 2. Sestiere's shops

\begin{tabular}{lrrrrrr}
\multicolumn{7}{c}{ Table 2. Sestiere’s shops } \\
\hline & $\mathbf{1 9 7 6}$ & $\mathbf{\%}$ & $\mathbf{2 0 0 7}$ & $\mathbf{0}$ & Total & $\mathbf{\%}$ \\
\hline Saint Mark & 1010 & 27.23 & 1078 & 27.95 & 68 & 6.73 \\
Cannaregio & 774 & 20.87 & 697 & 18.07 & -77 & -9.95 \\
Castello & 756 & 20.38 & 693 & 17.97 & -63 & -8.33 \\
San Polo & 460 & 12.40 & 593 & 15.37 & 133 & 28.91 \\
Dorsoduro & 385 & 10.38 & 451 & 11.69 & 66 & 17.14 \\
Santa Croce & 219 & 5.90 & 278 & 7.21 & 59 & 26.94 \\
Giudecca & 105 & 2.83 & 67 & 1.74 & -38 & -36.19 \\
Total & $\mathbf{3 7 0 9}$ & $\mathbf{1 0 0 . 0 0}$ & $\mathbf{3 8 5 7}$ & $\mathbf{1 0 0 . 0 0}$ & $\mathbf{1 4 8}$ & $\mathbf{3 . 9 9}$ \\
\hline
\end{tabular}


The analysis allows for further considerations, especially with regard to distribution in the urban context (Table 2). It is particularly evident how some Sestieri have become increasingly marginalized. Those Stestieri that are seriously suffering as a result of the population bleed, and consequently show a negative trend with regard to the number of shops, are those that in the past were highly residential: Castello, Cannaregio, and Giudecca. Furthermore, these Sestieri have not been subjected to the phenomenon of tourism reshaping, with the exception of some parts of Cannaregio and the central areas of Castello.

With regard to the analyses presented - one related to macro-categories and the other based on a territorial investigation - it is of further interest to present a more detailed analysis concerning the importance of each macrocategory per Sestiere.

The Tourist Stores The first macro-category observed refers directly to tourism. Tourist linked activities have shown the most sizeable growth within the city as a whole. The number of stores increased by 694 units between 1976 and 2007, determining a +229\% variation (Table 1). Considering the total distribution of the outlets, those dedicated to the tourist sector shifted from $8.17 \%$ in 1976, to 25.85\% in 2007 (Table 1).

As well as considering the macro-data, it is also be interesting to observe the composition of these shops. With this in mind, we have distinguished two sub-categories. On one hand are what can be described as "banal shops" which include mass produced souvenirs, common paintings and sketches, and the multitude of articles sold by hawkers (excluding clothes). While on the other hand, we have the "traditional stores" represented by antique dealers, art galleries, and traditional, high quality Venetian products.

Table 3. Banal tourist shops

\begin{tabular}{lrrrrrr}
\hline & & & & & \multicolumn{2}{c}{$\boldsymbol{2 0 0 7 - 1 9 7 6}$} \\
\hline & $\mathbf{1 9 7 6}$ & $\mathbf{\%}$ & $\mathbf{2 0 0 7}$ & \% & Total & $\%$ \\
\hline Saint Mark & 108 & 53.20 & 258 & 34.82 & 150 & 138.89 \\
San Polo & 27 & 13.30 & 142 & 19.16 & 115 & 425.93 \\
Cannaregio & 26 & 12.81 & 109 & 14.71 & 83 & 319.23 \\
Castello & 24 & 11.82 & 137 & 18.49 & 113 & 470.83 \\
Santa Croce & 12 & 5.91 & 44 & 5.94 & 32 & 266.67 \\
Dorsoduro & 6 & 2.96 & 49 & 6.61 & 43 & 716.67 \\
Giudecca & 0 & 0.00 & 2 & 0.27 & 2 & n.a. \\
Total & $\mathbf{2 0 3}$ & $\mathbf{1 0 0 . 0 0}$ & $\mathbf{7 4 1}$ & $\mathbf{1 0 0 . 0 0}$ & $\mathbf{5 3 8}$ & $\mathbf{2 6 5 . 0 2}$ \\
\hline
\end{tabular}

Bearing in mind this distinction, further considerations can be made: 538 units out of 694 (total incremental variation) are dedicated to "banal" articles (Table 3). The latter are low in both quality and price. Many of the articles sold in these shops are considered to be typically Venetian specialties, while the products, in reality, bear no relationship to local 
products and have no artistic value. This becomes less evident in the Sestiere of St. Mark's, where the number of "banal" stores dropped from $53 \%$ of total stores in 1976 to almost 39\% in 2007. Nevertheless, this Sestiere has revealed the highest growth rate compared to the rest of the city, with 150 new stores. San Polo is in second place, thanks to the pedestrian pathway carved out by the flow of tourists arriving from the Scuola Grande di San Rocco (School of Saint Rocco) and heading towards the Rialto Bridge. Third in line is the increase registered at Castello attributed to the re-shaping of the urban areas; especially around St. Mark's Square and along the waterfront (Riva degli Schiavoni, Ruga Giuffa, San Zaccaria, and Bragora) from St. Mark’s Square to the Giardini (where part of the Biennale takes place), and near the Arsenale.

One of the most significant transformations has taken place in Cannaregio where the increment is exclusively focused on the Strada Nova pathway between the railroad station and the Rialto Bridge, while the other areas, such as the Sestiere of Castello, remain heavily marginalized.

A more limited development can be observed with regard to the traditional tourist shops. The total number of new stores is 156 which represents an incremental variation of $+156 \%$ (Table 4). It is important to point out that the quasi totality of growth is related to new traditional Venetian products, rather than to antiques and art galleries. Recently, it is in fact more and more frequent to come across high quality mask stores with incorporated workshops, set up by people who have acquired related skills at Academy of Art. Unfortunately, the high quality stores dedicated to traditional skills such as lace-making and glass-blowing are in constant decline.

Table 4. Traditional tourist shops

\begin{tabular}{lrrrrrr} 
& \multicolumn{7}{c}{ Table 4. Traditional tourist shops } \\
\hline & $\mathbf{1 9 7 6}$ & $\mathbf{\%}$ & $\mathbf{2 0 0 7}$ & $\mathbf{0}$ & Total & \% \\
\hline Saint Mark & 56 & 56 & 122 & 47.66 & 66 & 117.86 \\
Dorsoduro & 13 & 13 & 61 & 23.83 & 48 & 369.23 \\
Castello & 11 & 11 & 22 & 8.59 & 11 & 100.00 \\
San Polo & 11 & 11 & 18 & 7.03 & 7 & 63.64 \\
Cannaregio & 8 & 8 & 27 & 10.55 & 19 & 237.50 \\
Giudecca & 1 & 1 & 2 & 0.78 & 1 & 100.00 \\
Santa Croce & 0 & 0 & 4 & 1.56 & 4 & n.a. \\
Total & $\mathbf{1 0 0}$ & $\mathbf{1 0 0}$ & $\mathbf{2 5 6}$ & $\mathbf{1 0 0 . 0 0}$ & $\mathbf{1 5 6}$ & $\mathbf{1 5 6 . 0 0}$ \\
\hline
\end{tabular}

Public Shops The second macro-category, which refers to public shops, has revealed a positive trend of +189 units with an increment of around $+27.5 \%$ over the thirty year period in consideration (Table 1 ). Also in this case, the typology has been dived into two sub-categories based on the service being offered. The first regards the prevalence of products consumed standing up. This sub-category includes bars, pubs, fast foods, pizza takeaways, kebab stores, pastries, and ice-cream parlors. The second sub- 
category refers to the majority of products consumed sitting down and includes pizzerias and restaurants.

Although it is difficult to establish a real distinction between the consumers of these products, we can say that the first sub-category is dedicated both to tourists, work-commuters and partially to residents, while the second sub-category is principally dedicated to tourists.

Table 5. Public shops (standing up)

\begin{tabular}{lrrrrrr}
\hline & & & & & \multicolumn{1}{c}{$\mathbf{2 0 0 7 - 1 9 7 6}$} \\
\hline Cannaregio & 1976 & \% & $\mathbf{2 0 0 7}$ & \% & Total & \% \\
Castello & 109 & 24 & 99 & 19.60 & -10 & -9.17 \\
Saint Mark & 84 & 18 & 100 & 19.80 & 16 & 19.05 \\
Dorsoduro & 62 & 14 & 84 & 16.63 & 22 & 35.48 \\
San Polo & 50 & 11 & 66 & 13.07 & 16 & 32.00 \\
Santa Croce & 31 & 7 & 49 & 9.70 & 18 & 58.06 \\
Giudecca & 16 & 3 & 12 & 2.38 & -4 & -25.00 \\
Total & $\mathbf{4 5 8}$ & $\mathbf{1 0 0}$ & $\mathbf{5 0 5}$ & $\mathbf{1 0 0 . 0 0}$ & $\mathbf{4 7}$ & $\mathbf{1 0 . 2 6}$ \\
\hline
\end{tabular}

By separately analyzing the two sub-typologies, further considerations emerge. In the first case in particular, (Table 5) the percentage of the stores reveals that in 2007 they appeared to be equally distributed between the Sestieri, with the exception of Santa Croce and Giudecca where products consumed standing up represent less than $10 \%$ respectively. Although the total growth of new shops is not particularly high (+47 units), the motivation behind the location of the outlets is quite different. The Sestiere of St. Mark's has increased its number of outlets thanks to its centrality and the consequent concentration of tourists in the area. Santa Croce, however, owes the almost $+60 \%$ increase to the presence of public offices and the University. Increments related to San Polo and Dorsoduro are mostly linked to work-commuters, apart from some areas which are more closely influenced by tourist flows, especially those which are tourist pathways. The sub-category which includes restaurants and pizzerias has registered an increment of +142 units with a total positive variation of around $+62 \%$. This sub-typology is the result of the conversion of a number of old bars and inns.

In addition, the type of services on offer has changed. There is an increase in eateries offering 'fixed menus' aimed at satisfying a consumer demand which classic or traditional menus were unable to cater for. 'Fixed menus' are directed to both tourists and work-commuters alike. In fact, the areas that incremented these services are not central tourist areas or marginal areas, but those that present the most sizeable tourist flows and where public offices and University-related buildings are located. 
Table 6. Public shops (sitting down)

\begin{tabular}{lrrrrrr}
\hline & & & & & \multicolumn{1}{c}{$\mathbf{2 0 0 7 - 1 9 7 6}$} \\
\hline Saint Mark & $\mathbf{1 9 7 6}$ & $\mathbf{\%}$ & $\mathbf{2 0 0 7}$ & \% & Total & $\%$ \\
Castello & 76 & 33 & 80 & 21.51 & 4 & 5.26 \\
Cannaregio & 47 & 20 & 78 & 20.97 & 31 & 65.96 \\
Dorsoduro & 21 & 20 & 81 & 21.77 & 34 & 72.34 \\
Santa Croce & 18 & 8 & 29 & 7.80 & 11 & 61.11 \\
San Polo & 12 & 5 & 47 & 12.63 & 35 & 291.67 \\
Giudecca & 9 & 4 & 7 & 1.88 & -2 & -22.22 \\
Total & $\mathbf{2 3 0}$ & $\mathbf{1 0 0 , 0 0}$ & $\mathbf{3 7 2}$ & $\mathbf{1 0 0 . 0 0}$ & $\mathbf{1 4 2}$ & $\mathbf{6 1 . 7 4}$ \\
\hline
\end{tabular}

Clothes' Stores. The third category is dedicated to apparel. In 2007, the typology accounted for around $15 \%$ of the total stores in Venice (Table 1). The increment is not particularly incisive and in actual terms represents 57 new units in the whole island, 38 of which (67\% of the total variation) are to be found in the Sestiere of St. Mark's (Table 7).

The high level of concentration in the Sestiere of St. Mark's is simply due to the centrality of the area. It is in this Sestiere that the most important, specialized boutiques and up-market Italian fashion shops are to be found. The most important Italian designer label boutiques such as Armani, D\&G, Prada, Valentino, Missoni, etc. are concentrated along the 200 metre-long Calle San Moisè, which is in close proximity to, and leads to, St. Mark's Square. Indeed, the increased visibility and prestige of the area play a fundamental role. Thus, despite the high overheads and sales targets, this area represents a global 'window' for the Italian fashion retailers.

Table 7. Clothes’ shops

\begin{tabular}{lrrrrrr}
\hline & \multicolumn{1}{c}{} & & & \multicolumn{2}{c}{$\boldsymbol{\mathbf { 2 0 0 7 - 1 9 7 6 }}$} \\
\hline & $\mathbf{1 9 7 6}$ & $\mathbf{\%}$ & $\mathbf{2 0 0 7}$ & \% & Total & $\%$ \\
\hline Saint Mark & 205 & 39 & 243 & 41.47 & 38 & 18.54 \\
Cannaregio & 99 & 19 & 97 & 16.55 & -2 & -2.02 \\
Castello & 84 & 16 & 83 & 14.16 & -1 & -1.19 \\
San Polo & 77 & 15 & 90 & 15.36 & 13 & 16.88 \\
Dorsoduro & 37 & 7 & 42 & 7.17 & 5 & 13.51 \\
Santa Croce & 17 & 3 & 28 & 4.78 & 11 & 64.71 \\
Giudecca & 10 & 2 & 3 & 0.51 & -7 & -70.00 \\
Total & $\mathbf{5 2 9}$ & $\mathbf{1 0 0 . 0 0}$ & $\mathbf{5 8 6}$ & $\mathbf{1 0 0 . 0 0}$ & $\mathbf{5 7}$ & $\mathbf{1 0 . 7 8}$ \\
\hline
\end{tabular}


The upturn in San Polo is more closely related to the hoards of tourists that cross the area in order to reach the Rialto Bridge from San Rocco. In this part of the city, apparel stores tend to specialize in casual fashion.

Finally, the modest augmentation (+11 new units) in Santa Croce is almost certainly the only case in Venice which most probably targets the resident population.

Grocery's Stores The fourth category is dedicated to grocery stores. This sector has suffered the greatest loss of shops. The total of this macrotypology passed from 19.41\% in 1976 to $7.16 \%$ in 2007 (Table 1). Grocery stores represent a decrease of -444 units, equivalent to $-61.67 \%$ (table 8). In fact, there has been a negative trend in each Sestiere. In particular, the residential Sestieres such as Castello, Canareggio, and Dorsoduro are those that been more deeply affected. It is possible to affirm that these stores have been partially re-converted into tourist shops, while marginal areas have registered high levels of 'commercial mortality'. Santa Croce has definitely suffered due to the closure of many outlets as a result of its exclusion from the tourist pathways. Conversely, San Polo has limited the damage thanks to its residential centrality and an upturn in the flux of tourists, especially related to the pedestrian pathway leading from San Rocco to the Rialto Bridge. The Sestiere of St. Mark's has also seen a sizeable decrease in grocery stores as its focal point as a tourist destination increases. Lastly, the Giudecca has registered a negative $-54.29 \%$. This is a very interesting result if we consider the strong prevalence of residential accommodation on the island. However, we must also consider the fact that the residents of the Giudecca frequently commute to and from the main island and often prefer to shop over there.

Table 8. Grocery’s stores

\begin{tabular}{lrrrrrr}
\hline & \multicolumn{1}{c}{$\boldsymbol{c}$} & \multicolumn{3}{c}{$\boldsymbol{\Delta} \mathbf{2 0 7 - 1 9 7 6}$} \\
\hline & $\mathbf{1 9 7 6}$ & $\mathbf{\%}$ & $\mathbf{2 0 0 7}$ & $\%$ & Total & $\%$ \\
\hline Castello & 189 & 26 & 65 & 23.55 & -124 & -65.61 \\
Cannaregio & 165 & 23 & 56 & 20.29 & -109 & -66.06 \\
Dorsoduro & 110 & 15 & 29 & 10.51 & -81 & -73.64 \\
San Polo & 105 & 15 & 79 & 28.62 & -26 & -24.76 \\
Saint Mark & 60 & 8 & 14 & 5.07 & -46 & -76.67 \\
Santa Croce & 56 & 8 & 17 & 6.16 & -39 & -69.64 \\
Giudecca & 35 & 5 & 16 & 5.80 & -19 & -54.29 \\
Total & $\mathbf{7 2 0}$ & $\mathbf{1 0 0 . 0 0}$ & $\mathbf{2 7 6}$ & $\mathbf{1 0 0 . 0 0}$ & $\mathbf{- 4 4 4}$ & $\mathbf{- 6 1 . 6 7}$ \\
\hline
\end{tabular}

The Dynamic of the Pathways 
Lando sustains that "in every urban structure there is generally a hierarchical system of links and functions that generate either a concentration or peripherarization process which is triggered by the preference of specific pathways in specific areas” (1999:381).

This is also true with regard to Venice and for two principal reasons, namely the structure of the city and its characteristics. Firstly, the two gateways (the bus station at Piazzale Roma and the Rail Station) to and from the historical city centre determine clear pathways towards the main destinations of the city. Secondly, the entire urban system is based on pedestrian traffic which allows for a much higher impact on the commercial structure compared to any other transport system available in a city.

Russo (2002) highlights another important phenomenon that concerns Venice's historical city centre; the under-exploitation of some cultural areas and the over-exploitation of others. This acerbates the pathway creation process with a view to making the better known, or more important, cultural institutions and areas more easily accessible. This in turn increases the negative externalities in those specific zones.

In order to better understand the effects of this phenomenon on the commercial structure, five principal pathways have been identified (Figure 1): Rail Station $>$ Rialto Bridge; Bus Station $>$ San Rocco $>$ Rialto Bridge; Mercerie; Saint Mark’s $>$ Accademia Art Gallery; Rialto Bridge $>$ Campo Morosini (towards Accademia Art Gallery).

The entire system of the retail shops related to the pathways is presented in Table 9. The data reveals that the total amount of shops located along the pathways is a ratio of one to three of the entire commercial structure of the city. The percentage, which refers to the total system, has remained virtually unchanged according to the figures revealed in the two censuses. The composition of macro-categories has, however, changed resulting in the modification of the commercial structure.

More specifically, the increase in tourist oriented stores has increased at a lower rate compared to total store increase $(+193.5 \%)$. This figure is also supported by the percentage of pathway stores which dropped from almost $46 \%$ in 1976 to less than $41 \%$ in 2007 . Bearing in mind the total rise in the number of tourist stores, we can see that they span the entire city, with the exception of the more marginalized areas.

Public shops have increased by $+33.6 \%$ over the thirty year period in question, compared to total variations which have occurred in the city (circa $+27.5 \%$ ). The $+1 \%$ increase along the pathways demonstrates that the general distribution has remained more or less constant. There does, however, appear to be a greater propensity towards locating more stores along the major pathways than in the previous census.

Concerning apparel stores, the variation is double the total increment registered in the city. Furthermore, the concentration covers more than $53 \%$ of the clothes stores of the entire Venetian store network. Therefore, the concentration of this category along the pathways is apparent (later analyzed in more detail).

The grocery stores remain on a par with the total negative variation trend (around -61\%) and their concentration ratio is about one to five of the entire 
system. Although they appear to be high distribution performers along the pathways, it is important to note the presence of many grocery stores exclusively dedicated to Italian delicacies but which appear to cater more to the tastes of the tourist rather than to the demand of the residents.

Other shops have seen a decrease of $-41 \%$, which is more than the total decrement registered in the city $(-23.7 \%)$. Compared to the total store system, the concentration of shops has shifted downward from $35.8 \%$ to $27.7 \%$. This category is a perfect example of the impact tourism has had, at least along the main pathways.

Table 9. Total retail shops along the pathways

\begin{tabular}{lrrrrrrr}
\hline & \multicolumn{1}{c}{ Total } & \multicolumn{1}{c}{$\%$} & \multicolumn{3}{c}{ Pathways } \\
& \multicolumn{1}{c}{ Pathways } & Variation & Total shops & \multicolumn{2}{c}{ Total shops } \\
\hline & $\mathbf{1 9 7 6}$ & $\mathbf{2 0 0 7}$ & $\mathbf{2 0 0 7 - 1 9 7 6}$ & $\mathbf{1 9 7 6}$ & $\mathbf{2 0 0 7}$ & $\mathbf{1 9 7 6}$ & $\mathbf{2 0 0 7}$ \\
\hline Tourist shops & 139 & 408 & 193,5 & 303 & 1003 & 45,9 & 40,7 \\
Public shops & 152 & 203 & 33,6 & 688 & 877 & 22,1 & 23,1 \\
Clothes' shops & 258 & 312 & 20,9 & 529 & 586 & 48,8 & 53,2 \\
Grocery stores & 146 & 57 & $-61,0$ & 720 & 276 & 20,3 & 20,7 \\
Other shops & 526 & 310 & $-41,1$ & 1469 & 1121 & 35,8 & 27,7 \\
Total & $\mathbf{1 2 2 1}$ & $\mathbf{1 2 9 0}$ & $\mathbf{5 , 7}$ & $\mathbf{3 7 0 9}$ & $\mathbf{3 8 6 3}$ & $\mathbf{3 2 , 9}$ & $\mathbf{3 3 , 4}$ \\
\hline
\end{tabular}

Further considerations can be made by observing the composition of the stores along each pathway.

The first pathway (Rail Station>Rialto Bridge) is 1,570 meters long. The total number of outlets on either side of the route are 394 which means one shop per 4 linear meters. The path is strongly affected by "banal” tourist shops which represented more than $22 \%$ of the weight of the total pathway in 2007 and an increase of $+15.9 \%$ during the period $1976-2007$. Despite this result, the remaining store categories represented the highest distribution value of the pathway, standing at $26.4 \%$ in 2007 . However, this macro-category's $-17.2 \%$ marks the biggest decrease during the thirty year period. In 2007, grocery stores along this route represented nearly $7 \%$ of total stores, resulting in a decrease of $-8.2 \%$. Both clothes stores and public shops (take-aways) which impacted for a total of around $20 \%$ and $14.2 \%$ respectively in 2007, remained unaltered compared to data for 1976 . This evolution represents an evident transformation of land use along the first pathway as far as tourism is concerned. In particular, the high level of "banal" tourist shops is blatantly evident. This phenomenon is probably related to tourists' attitude towards shops and shopping on their way back towards the rail gateway and the amount of time they still have available.

The second pathway (Bus Station $>$ Saint Rocco $>$ Rialto Bridge) covers about 1,710 meters. There are 373 stores on either side of the route with one 
outlet per 4.6 linear meters. The dynamics are similar to those of the previous pathway, but with a higher concentration of "banal" tourist shops. In fact, "banal" tourist shops represented $36.7 \%$ in terms of value in 2007 , up by $+36 \%$ compared to 1976 . The other shops that accounted for $21.7 \%$ in 2007 decreased by $-11 \%$ during the thirty-year observation period. The limited presence of grocery stores in 2007 showed a decrease of $-15.3 \%$ to $3.8 \%$ Apparel stores and public shops (take-aways) whose respective values of importance along the second pathway were $20.9 \%$ and $10.7 \%$, registered increases of $+3.5 \%$ and $+4.2 \%$ respectively. The greater presence of "banal" tourist stores compared to the previous scenario is linked to the arrival of tourists reaching Venice by tourist buses and coaches and whose spending power is of a different level.

The third pathway (Mercerie) is about 790 meters long. It undoubtedly has the highest density of outlets compared to the other pathways. There is a total of 263 stores spread along either side of the pathway which means one shop per 3 linear meter. This pathway is represented by three macrocategories in particular. "Banal" shops represent a value of more than 25\%, which, when added to the total of traditional tourist shops, gave a figure of $34.6 \%$ in 2007. The increase of both these macro-categories over the thirty year period was around $+10 \%$ and $+9 \%$ respectively. The second store type, in order of importance in this area, regards apparel which reached a total value of $35.4 \%$, an increment of $+11.3 \%$ compared to 1976 . The last macrocategory groups together "other" shops with a relevance of $22.8 \%$ marking a decrease of $-23.8 \%$ in the period considered. The specificity of this area is clearly represented by the first two macro-typologies of stores: tourist and apparel stores. It is evident that this zone is completely dedicated to tourists due to its centrality and its proximity to Saint Mark's Square (the main and final destination of visitors to Venice). Tourists who reach this part of the city have nearly arrived at their final destination and have more time to dedicate to looking at stores and shopping.

The fourth pathway (Saint Mark's>Accademia Art Gallery) is about 800 meters long. The total number of shops on both sides of the route is 126 with the presence of one shop per 6.3 linear meter. The whole pathway presented a $-6.7 \%$ decrease in 2007 compared to 1976. Nonetheless, the effects of tourism on the area are evident. In fact, the concentration of clothes stores was $+25.4 \%$ in 2007 up $+11.1 \%$ compared to 1976 . The tourist shops are the second most important macro-category. "banal" and traditional stores together total 34.1\%. The two sub-typologies are basically well balanced, even if the former has showed an increase of almost $+10 \%$ over the last thirty years, while the latter decreased by $-0.7 \%$. The last significant macro-category comprises "other" shops, with a presence of $23.8 \%$ showing a decrement of more than $-25 \%$ in the period considered. The increased importance of tourism is quite noticeable along this pathway. In addition, it also has a much higher concentration of art shops compared to the other four pathways. This is attributable to two factors which are interlinked, namely its proximity to the Accademia Art Gallery, and the fact that 
this pathway has historically been the most important route between Saint Mark's Square and the Accademia Art Gallery. The decrease of "other" stores again confirms that this pathway is also influenced by the presence of tourists and any changes that take place are aimed at tourism.

The last pathway, the Rialto Bridge $>$ Campo Morosini (towards the Accademia Art Gallery) covers about 900 meters. There is a total of 134 stores on either side of the pathway and it presents a total store increase of about $+5 \%$. The concentration of outlets is one per 6.7 linear meter. The most significant macro-category is "other" shops which represented $26.1 \%$ in 2007, despite undergoing a $-15.6 \%$ decrease. The second most important macro-typology (apparel) stands at $23.1 \%$ with an increment of less than $+1 \%$ in the period taken into account. Finally, the total of tourist stores represents a value of $22.4 \%$ of which "banal" tourist shops account for $17.2 \%$. The latter typology represents the most important and unique increase of the area at $+15.6 \%$. It is indisputable that this pathway is undergoing transformation aimed at the tourists sector. In fact, the most obvious macro-typologies present in the zone are apparel and "banal" tourist shops. Nevertheless, the sizeable presence of other shops and the unaltered presence of grocery stores affirms that the residents' demand is still being supplied.

In short, we can state that there has been an obvious transformation along the major pathways regarding the number of "banal" tourist shops. This phenomenon increased less than in the city as a whole for two reasons: one is related to tourism trends which had already modified in the past; the other is linked to a sprawl of tourist stores across the city. It has also been possible to observe the concentration of other typologies of tourist oriented stores such as clothes stores and public stores. Conversely, stores supplying goods to satisfy the demands of the resident population have declined in importance. With particular reference to the grocery stores, the decrement reflects that registered in the rest of the city, while the reduction of other shops is much more evident ranging from about $-24 \%$ at the city level to $41.1 \%$ along the pathways.

\section{Conclusion}

Increasing numbers tourists and the changing trends of the tourism sector are two of the most important characteristics which have affect all tourist destinations since the Second War World. This is particularly true when referred to art cities. Consequently, the tourism sector has strongly impacted on the evolution of Venice and its historical city centre in particular. This evolution has influenced the urban structure of the city with the creation of new areas (or the refurbishment of abandoned production areas) dedicated exclusively to tourists; the new design and architecture of city zones in order to improve its image; the transformation of the commercial structure which adapts to satisfy the tourist demand. The latter aspect has been analyzed with regard to Venice's historical city centre. 
The purpose of this research was to better understand the potential impact of tourism on the commercial structure of the city. The analysis concentrated on three areas of potential demand: tourists, residents, and work-commuters and used information gathered from censuses carried out in 1976 and 2007 respectively as well as the type of merchandise displayed in the shop windows. The results are very interesting. First of all, it is possible to monitor the increase of stores dedicated to tourists. In particular, the prominence of the total number of grocery stores versus tourist stores present in 2007 has almost reversed compared to 1976. Furthermore, the progressive marginalization of some areas (those exclusively supplying residents' demand) excluded from the tourist routes was also brought to light. "Banal" stores showed an increase compared to previous years and the position of public stores is also interesting. There has been a visible increase in the number of restaurants and pizzerias, many of which are now installed in refurbished inns or bars, which are a direct result of the need to address the demand of both tourists and work-commuters. Tourism has also triggered an increase in the number of clothes stores, especially in the central zone, and mainly comprises branches of well-known Italian stores.

Similar considerations have been confirmed with regard to the five major pathways that cross the city. In particular, there has been a noticeable shift, along these routes, towards satisfying tourist demand, which has reduced the supply of resident-oriented goods and products.

This analysis has allowed for a better understanding of the impact of tourism and should be applied to other cities that are in a similar situation, such as Milan, Florence, and Rome whose historical centers are bordered by peripheral walls. Although Venice is unique compared to other realities, especially if we consider the way people perceive the value of both the city as a whole and its historical centre, the conceptual model is the same: the effects of tourism on the city centre. After the Second War World, city centers began to sprawl over the territory subsequent to the need for industries to find new areas outside the city centre. Consequently, tertiary activities were prevalently located in city centers. The most evident consequence was the replacement of industrial activities with other activities which generated higher revenues linked to real estate and thus the tertiary sector. As a result, higher real estate prices caused the population to migrate outside the city perimeters leading to the depopulation of the historical centers. The latter, now the heart of "new" transformed cities, started to experience a two-sided phenomenon. During the day they are crowded with the hustle and bustle of people working or shopping there, while during the evening and at the night they become deserted. It is precisely at this moment that the tourism sector can play an important role in revitalizing historical city centers throughout the various periods of the day and the year, and thus slowdown depopulation. It is, however fundamentally important to make clear choices regarding the type of tourism to favor.

In the case of Venice, its strong dependency on tourism has lead it to specialize in the tertiary sector and, in certain cases, this has allowed it to hold on to a part of the population thanks to the opportunity for higher incomes and the availability of jobs - far more so than it would have done 
without tourism. Furthermore, considering the type of receptivity in the area, we can assume that some residents remain in Venice thanks to the opportunity that property owners have of renting out rooms or opening B\&Bs.

Although the negative effects that tourism has on the city undoubtedly predominate, the positive hypothesis previously presented is unfortunately rarely taken into consideration. It remains in strong antithesis with the common idea of the impoverishment of the quality of life of the residents and the city's economy determined by tourism. In fact, we believe that rather than focusing exclusively on the negative factors, an accurate analysis of both the positive and the negative effects of tourism has to be carried out in order to shed more light on the issue. This approach should make it easier for the authorities to make clear choices and decide on appropriate steps in order to identify the most appropriate type of tourism that the city would like to attract. If Venice intends to base its tourist economy on mass tourism, without finding ways of stemming the flow of day-trippers, the negative external effects will continue to increase, together with depopulation and the standardization of knowledge and skills present in the city. Conversely, should Venice decide to attract specific tourists, such as those who own second homes there, long-stay tourists, and those who come to Venice for specific events, it will have to make very clear choices especially with regard to regulating the tourist flow by developing and implementing ad hoc policies and strategies. 


\section{REFERENCES}

Barbiani, E. and G. Zanon, 2004, Condizioni di Competitività delle Strutture Ricettive del Comune di Venezia e della Regione Turistica, CISETCOSES Report No. 536. Venice: CISET-COSES.

Bonetti, E., 1971, “Le Attività al Dettaglio e la loro Localizzazione”. Paper Proceeding of $X X^{\circ}$ Congresso Geografico Italino 4:27-36. Società Geografica Italiana: Roma.

Butler, R. W., 1980, “The Concept of a Tourist Area Cycle of Evolution: Implications for Management of Resources”, Canadian Geographer, 24(1):5-12.

Comune di Venezia, 2006, "Una Stima della Popolazione Presente nel Comune di Venezia", <http://www.comune.venezia.it/statistica> (20 November 2007)

Costa, P. and F. Lando and G. Zanetto, 1980, "Rinnovo Urbano e Trasformazioni Sociali nel Centro Storico di Venezia”, Sistemi Urbani, 2/3:385-410.

Costa, P. and J. Van der Borg, 1988, "Un Modello Lineare per la Programmazione del Turismo: sulla Capacità Massima di Accoglienza Turistica del Centro Storico di Venezia”, COSES Informazioni 32/33:2126.

Knox, P. L., 1991, "he Restless Urban Landscape. Economic and Sociocultural Change and the Transformation of Metropolitan Washington, DC”, Annals of the Association of American Geographers, 81:181-209.

Lando, F., 1999, “Turismo e Trasformazioni dello Spazio Urbano. Il caso di Venezia Centro Storico”, in Scritti Geografici in Ricordo di Mario Ortolani, Memorie della Società Geografica Italiana Vol. LXI, P. Dagradi, eds., pp.371-393. Roma: Società Geografica Italiana.

Lando, F. and G. Zanetto, 1978, "Le Migrazioni da e per Venezia Insulare”, in Italiani in Movimento, G. Valussi, eds., pp.327-330. Pordenone: GEAP.

Manente, M. and D. Rizzi, 1993, “I Visitatori di Venezia: 1989-1992”. Working Paper No. 93/13, Department of Economics, University of Venice.

Manente, M. and F. Montaguti, 2004, “L’Impatto Economico del Turismo Veneziano”, Quaderni Insula VI/20:29-37.

Quinn, B., 2007, "Performing Tourism. Venetian Residents in Focus", Annals of Tourism Research 34(2): 458-476.

Raffestin, C., 1991a, “Il Ruolo delle Città d'Arte nell'Avvento di un'Economia di Contemplazione”, in La Regione Turistica, I. Ierace, eds., pp. 213-223. Padova: Cedam.

Raffestin, C., 1991b, "La Natura e il Ruolo della Città d'Arte nella Società Contemporanea”, in Il Turismo nelle Città d'Arte Minori, G. Zanetto and A. Calzavara, pp. 27-34. Padova: Cedam.

Russo, A. P., eds., 2002a, The Sustainable Development of Heritage Cities and Their Regions. Rotterdam: Tinbergen Institute. 
Russo, A. P., 2002b, "The Vicious Circle of Tourism Development in Heritage Cities", Annals of Tourism Research 29(1):165-182.

Van der Borg, J. and A. Costa, 2004, "Il Turismo a Venezia”, Quaderni Insula VI/20:29-37.

Van der Borg, J. and A. P. Russo, 2001, "Towards Sustainable Tourism in Venice”, in Sustainable Venice: Suggestions for the Future, I. Musu, eds., pp. 159-193. The Netherlands: Kluver Academic Publishers.

Van der Borg, J., eds., 1991, Tourism and Urban Development. Amsterdam: Thesis Publishers.

Zanetto, G. and A. Calzavara, eds., 1991, Il Turismo nelle Città d'Arte Minori. Padova: Cedam. 